\title{
Accuracy Of Ultrasound Prediction Of Fetal Maturity By \\ Ossification Center Of Long Bones in The Cases Of Elective \\ Cesarean Section At 38 Week Gestation
}

Aminah Abd EL-Fattah*, Lamyaa Yosry **, Zeinab Hammour

*** and Doaa AbdelAziz

Chararah****

*Assistant Professor of Obstetrics and Gynecology, ${ }^{* *}$ professor of Obstetrics and Gynecology and, ${ }^{* * *}$ professor of Community medicine, AL- AZHAR University, Faculty Of Medicine, ${ }^{* * * *}$ M.B.B.Ch -Resident of Obstetrics and Gynecology, General Monof Hospital
Corresponding author:

Aminah Abd EL-Fattah

Assistant Professor of Obstetrics and Gynecology

\begin{abstract}
$\underline{\text { Abstract }}$
Fetal lung maturity can be assessed by biochemical analysis of amniotic fluid, but it carries the potential for serious complications of amniocentesis .Efforts have been made to use prenatal diagnostic ultrasonography as a means of evaluating lung maturity. Ultrasonography, a non invasive and widely available method, would be more acceptable.
\end{abstract}

Objective: The aim of this study is to determine accuracy of sonographic prediction of fetal maturity by ossification center of long bone(femur ,tibia and humerus), to determine most accurate one in estimation of gestational age (GA) at 38 weeks to do elective cesarean section and evaluate if gestational age by obstetric ultrasound is corresponding to evaluation by neonatology specialist.

Methods: The study was conducted on 200 pregnant woman were delivered by elective cesarean section in General Monof and AL-Zahraa University Hospitals in the period from Februrary2017 to August2017.

All the mother where subjected to full history, examination(general-local), ultrasound examination for detection of(GA) by fetal biometry ,visualize and measure proximal ossification center of (tibia, humerus) and distal(femur). Then reassessment of (GA)and fetal maturity after delivery by neonatology specialist. We have 2 groups (mature \&immature) fetus according to(GA) of neonates, Apgar Score and the need of the neonates to NICU.

Results: We studied prospectively 200 pregnant women scheduled for elective cesarean section at 38 wks gestation and compared the sonographic epiphyseal findings with the results showing after delivery. we found 187 mature fetus with mean age (38)wks and 13 immature fetus with mean age( $36 \mathrm{wks}$ ) admitted in NICU. Immature group having distal femur epiphysis(DFE) (13/13) and proximal tibia epiphseal (PTE) ossification present in (12/13cases)but absent in(1/13)case while Proximal ossification center of humerus (PHE) was absent in $(0 / 13)$ immature fetus but(PHE) was present in 168 and absent in 19 mature fetus. While ossification center of femur and tibia present(187/187) mature fetus. Using cut off point of size distal Epiphyseal Ossification Center(EOC) of femur $(6.25 \mathrm{~mm})$ or more as good predictor of fetal maturity with sensitivity of $86.1 \%$ \& specificity of $70.4 \%$ \&area under the curve0.878. While cut off point of size proximal (EOC) of tibia $(<$ $5.05 \mathrm{~mm}$ ) predict fetal immature with sensitivity of $76.5 \%$ \& specificity of $61.5 \%$ \&area under the curve of 0.790 . 
While cut off point of size of proximal (EOC) of humerus between mature\& immature groups at 38 weeks gestation was found $<(1 \mathrm{~mm})$ is immature with sensitivity of $90 \%$ \& specificity of $100 \%$ \&area under the curve of 0.949 .

And best cut off points of total size (EOC) of femur, tibia\& humerus between mature \& immature groups was found $<(14.05 \mathrm{~mm})$ in immature fetus with sensitivity of $85 \%$ \& specificity of $70.2 \%$ \&area under the curve of 0.850 .

(EOC) of humerus was present in 168 mature fetus but absent in 32 fetus(19)mature \&(13) fetus immature so can use the presence of(EOC) of humerus as a best ultrasonographic sign for fetal maturity at $(>38)$ gestation but its absence not indicate fetal immaturity because it was absent in 19 case of mature fetus ,so can depends on size of distal (EOC) of femur $>(6.25 \mathrm{~mm})$ and total size of(EOC) of 3 long bones $>14 \mathrm{~mm}$, as tool for estimating of fetal maturity in the absence(EOC) of humerus.

Conclusion: Confirmation of fetal maturity obtained by fetal biometry and ultrasound visualization and measurement of size of the epiphyseal ossification centers of long bones (femur-tibia-humerus) can be used as a tool for estimation of fetal maturity at 38 wks before elective cesarean section.

Keywords: lung maturity, gestational age(GA), Proximal Epiphyseal ossification center(EOC) of femur, tibia, humerus. Neonatal intensive care unite ( NICU).

\section{Introduction}

The pulmonary system is among the last of the fetal organ systems to mature, both functionally and structurally. Because the immature pulmonary system may not oxygenate the neonate adequately, preterm birth can lead to significant neonatal morbidity or mortality (Gillen-Goldstein et al., 2016).

Several methods are described to evaluate fetal lung maturity (FLM) such as measurement of the lecithin/sphingomyelin (L/S) ratio, presence or absence of phosphatidylglycerol (PG), and lamellar body count in amniotic fluid which requires amniocentesis (Fariba et al., 2016).

Amniocentesis an invasive procedure, and associated with a small but real risk to pregnancy, including preterm labor, premature rupture of membrane, abruption placenta, and fetomaternal hemorrhage, in $7 \%$ of cases and (rarely) fetal or maternal mortality. In contrast, ultrasonography, a noninvasive and widely available method, would be more acceptable (Fariba et al., 2016).

Ultrasound (US) and Last menstrual period (LMP) play complementary roles in establishing gestational age (GA). The LMP provides a preliminary estimate, while the US findings are used to confirm or replace the GA based on the LMP (Saba et al., 2014).

However, the accuracy of US declines as the pregnancy advances, owing to the increasing biological variability in the size of the fetus and its parts. So much so that, in the third trimester, using the standard fetal biparietal diameter (BPD), femur length (FL) and abdominal circumference (AC) for assigning GA, the accuracy of US is +3-4 weeks. This range of $+3-4$ weeks creates problem for Obstetrician in deciding fetal maturity (Saba et al., 2014).

This problem is further compounded in our local circumstances; particularly in case of illiterate women, who neither remember their LMP, nor undergo for early US examinations and present themselves either directly at the time of labor or late complications (Saba et al., 2014).

In these situations among all the proposed US parameters for GA, none is very precise particularly when taken for the first time during the third trimester of pregnancy, leaving the obstetrician in a real quandary. The rationale of this study, therefore, is to have an additional parameter that may help to narrow this range in third trimester gestational age (Saba et al., 2014).

\section{Aim of the Work}

The aim of the work is to,

1. Evaluate sonographic prediction of fetal maturity by fetal biometry, ultrasound visualization and measurement of the epiphyseal ossification centers of long bones (femur-tibia-humerus)

2. Determine the most accurate one in estimation of gestational age (GA) at 38 weeks to do elective Cesarean section.

3. Evaluate of GA by obstetric US is corresponding or not to evaluation by neonatology specialist. 


\section{Patients and Methods}

The study was a prospective study and was performed on 200 pregnant women from General Monof and Al-Zahraa University Hospitals in the period from February 2017 to August 2017.

\section{Inclusion criteria:}

1. Singleton pregnancy.

2. Admitted cases to do elective C.S 38 weeks of pregnancy.

3. The difference between GA by LMP and by early obstetric US is not exceeding one week.

\section{Exclusion criteria:}

1. Multifetal pregnancy.

2. Gestational age other 38 weeks.

3. Intrauterine fetal death

4. Presence of other diseases with pregnancy as thyroid, heart, kidney.

5. Premature rupture of membranes.

6. Patients with unknown date or unsure of date.

7. Congenital malformations.

\section{All pregnant females were subjected to the fol- lowing:}

\section{History taking:}

- Complete personal profile.

- Complete obstetric history and past history (medical - surgical -drugs -allergies).

- Calculate weeks of pregnancy from LMP (to exclude patients with exclusion criteria).

2. General and obstetric examination.

3. Preadmission investigations $(\mathrm{CBC}, \mathrm{Rh}$ factor, FBS, PPBS, kidney, liver functions, clotting and bleeding time).

4. Preadmission U.S. to measure fetal maturity:

The ultrasound was performed using PREMIUM LOGIQ P5 2D Koreal ultrasound (General electric) with a 3.5-5 MHZ abdominal probe to measure:

- Visualization and measurement of ossification centers of long bones(femur-tibia and humerus ) . The ossification centers of distal femoral and proximal tibial epiphysis can be seen at the lev- el of knee joint as echogenic structure whereas the proximal humeral epiphysis is seen at shoulder joint. Measurements of the epiphysis were taken from the outer to outer margins in an axial plane along the medio-lateral surface of epiphysis. The exact identification was made by guiding the transducer along the largest axis of the femoral diaphysis avoiding oblique sectioning. Once the distal Epiphyseal Ossification Center (EOC) of femur was identified, the measurement was repeated 3 times and the largest diameter obtained was recorded. Measurements of the proximal tibial \& humerus epiphysis were obtained in a similar way.

5. Detection of GA by(BPD, FL,AC\& Fetal weight )and sonographic parameters of Ossification centers, and comparing them by GA from LMP and detection of the most accurate one.

6. Postnatal observation of neonates:

Post-partum evaluation of GA.

- Need for incubation or not and the cause.

- APGAR score at one. and five minutes

Data were collected, revised, coded and entered to the Statistical Package for Social Science (SPSS) version 16. The descriptive data about 200 pregnant women was collected and represented in tables and figures

\section{Results}

We studied prospectively 200 pregnant women scheduled for elective cesarean section at 38 wks gestation and compared the sonographic epiphyseal findings with the results showing after delivery. We found 187 mature fetus with mean age (38) wks and 13 immature fetus with mean age (36) wks admitted in NICU. Immature group having distal femur epiphysis (DFE) (13/13) and proximal tibia epiphyseal (PTE) ossification present in (12/13cases)but absent in(1/13)case while Proximal ossification center of humerus (PHE) was absent in (0/13) immature fetus but(PHE) was present in 168 and absent in 19 mature fetus. While ossification center of femur and tibia present in $(187 / 187)$ mature fetus. 
Table (1): General characters of the studied groups.

\begin{tabular}{|l|c|c|c|c|c|}
\hline \multicolumn{1}{|c|}{ Variables } & TN & Minimum & Maximum & Mean & Std. Deviation(SD) \\
\hline Age (years) & 200 & 21.00 & 37.00 & 27.175 & 3.26 \\
\hline Gravidity & 200 & 1.00 & 6.00 & 3.115 & .96 \\
\hline Parity & 200 & .00 & 5.00 & 1.880 & .81 \\
\hline Gestational age (weeks) & 200 & 36.00 & 38.00 & 37.870 & .49 \\
\hline Weight (gm) & 200 & 2800.00 & 3800.00 & 3109 & 205.79 \\
\hline APGAR Score 1 Min & 200 & 5.00 & 9.00 & 7.675 & .83 \\
\hline APGAR Score 5 Min & 200 & 5.00 & 9.00 & 8.415 & .86 \\
\hline
\end{tabular}

TN: Total number.

Table (2): Descriptive Statistics of sizes of ossification centers (femur, tibia and humerus).

\begin{tabular}{|l|c|c|c|c|c|}
\hline \multicolumn{1}{|c|}{ Variables } & TN & Minimum & Maximum & Mean & Std. Deviation(SD) \\
\hline Size of EOC of femur (mm) & 200 & 4.00 & 9.80 & 7.229 & 1.03 \\
\hline Size of EOC of tibia (mm) & 200 & 3.00 & 8.30 & 5.836 & 1.01 \\
\hline Size of EOC of humerus (mm) & 200 & 0.00 & 8.00 & 3.595 & 1.88 \\
\hline
\end{tabular}

EOC: Epiphyseal ossification center

TN:TotalNumber

Table (2) shows mean sizes of ossification centers of femur was (7.229) $\mathrm{mm}$, tibia(5.836)mm and mean of humerus ( 3.595$) \mathrm{mm}$.

Table (3): Correlation between EOC of tibia, EOC of humerus among the studied groups (mature \& immature groups).

\begin{tabular}{|l|c|c|c|c|c|}
\hline \multicolumn{1}{|c|}{ Items } & TN & Mean & Std. Deviation & r & Significance \\
\hline EOC of tibia & 200 & 5.836 & 1.0118 & $0.506^{* *}$ & 0.001 \\
\hline EOC of humerus & 200 & 3.595 & 1.8762 & $0.232^{* *}$ & 0.000 \\
\hline
\end{tabular}

EOC: Epiphyseal Ossification Center (mm)

r: Correlation coefficient

Table (3) shows significant statistical relation between (EOC) of tibia, humerus, among the studied groups ( mature \& immature) groups.

Table (4): Comparison between( mature and immature) groups regarding presence of (EOC) of femur, tibia and humerus.

\begin{tabular}{|c|c|c|c|c|c|c|c|}
\hline \multirow{2}{*}{\multicolumn{2}{|c|}{ Variables }} & \multicolumn{2}{|c|}{ Mature } & \multicolumn{2}{|c|}{ Immature } & \multicolumn{2}{|c|}{ Test of significance } \\
\hline & & No.(187) & $\%$ & No.(13) & $\%$ & Chi-sq $X^{2}$ & P-value \\
\hline \multirow{2}{*}{$\begin{array}{l}\text { Ossification center } \\
\text { at femur }(\mathrm{mm})\end{array}$} & Absent & 0 & $0.0 \%$ & 0 & $0.0 \%$ & \multirow[t]{2}{*}{1} & \multirow{2}{*}{ f-varue } \\
\hline & Present & 187 & $100.0 \%$ & 13 & $100.0 \%$ & & \\
\hline \multirow{2}{*}{$\begin{array}{l}\text { Ossification center } \\
\text { at tibia }(\mathrm{mm})\end{array}$} & Absent & 0 & $0.0 \%$ & 1 & $7.7 \%$ & \multirow{2}{*}{14.46} & \multirow{2}{*}{0.065} \\
\hline & Present & 187 & $100.0 \%$ & 12 & $92.3 \%$ & & \\
\hline \multirow{2}{*}{$\begin{array}{l}\text { Ossification center at } \\
\text { humerus (mm) }\end{array}$} & Absent & 19 & $10.2 \%$ & 13 & $100.0 \%$ & \multirow{2}{*}{62.626} & \multirow{2}{*}{0.000} \\
\hline & Present & 168 & $89.8 \%$ & 0 & $0.0 \%$ & & \\
\hline
\end{tabular}

EOC: Epiphyseal Ossification Center ( $\mathrm{mm}$ )

Table (4) shows that there was no statistical significant difference found between mature and immature groups regarding presence of EOC of tibia which was present in 187/187 cases (100\%) of mature group and also present in $12 / 13$ cases $(92.3 \%)$ of the immature group but absent only in $1 / 13$ case $(7.7 \%)$ of immature group and there was highly statistical significant difference found between mature and 
immature groups regarding presence of EOC of humerus. immature groups regarding presence of EOC of humerus which was present in $168 / 187$ cases $(89.8 \%)$ and absent in $19 / 187(10.2 \%)$ cases of mature group versus the immature group which was absent in all cases $13 / 13(100 \%)$ with p-value 0.000 and while no difference noticed between the two groups regarding presence of EOC of femur which was present in both mature and immature groups.

Table (5): Mean of total sizes of ossification centers of three bones (femur, tibia and humerus) among the studied groups (mature \& immature ).

\begin{tabular}{|c|c|c|c|c|c|c|}
\hline \multirow{2}{*}{ Variable } & \multirow{2}{*}{$\begin{array}{c}\text { Studied } \\
\text { groups }\end{array}$} & \multirow{2}{*}{$\mathbf{T N}$} & \multirow{2}{*}{$\begin{array}{c}\text { Mean } \\
\operatorname{size}(\mathbf{m m})\end{array}$} & \multirow{2}{*}{ Std. Deviation } & \multicolumn{2}{|c|}{ Test of significance } \\
\hline & & & & & t-test & p-value \\
\hline \multirow{2}{*}{$\begin{array}{l}\text { Total sizes of EOC of three } \\
\text { bones (femur, tibia and } \\
\text { humerus) }\end{array}$} & Immature & 13 & 12.269 & 3.63120 & \multirow{2}{*}{-5.639} & \multirow{2}{*}{0.000} \\
\hline & Mature & 187 & 16.982 & 2.86095 & & \\
\hline
\end{tabular}

EOC: Epiphyseal ossification center (mm)

Table (5) shows the mean of total sizes of ossification centers of three bones (femur, tibia and humerus) $12.27 \mathrm{~mm}$ in immature group versus $16.98 \mathrm{~mm}$ in mature group and there was highly statistically significant difference between (mature \& immature) groups.

Table (6): Mean of gestational age, weight, APGAR Score at $1 \mathrm{~min}$ and APGAR Score at 5 min among the studied groups (mature \& immature babies).

\begin{tabular}{|l|c|c|c|c|}
\hline Items & Studied groups & TN & Mean & Std. Deviation \\
\hline \multirow{2}{*}{ Gestational age (GA) by weeks } & Immature & 13 & $\mathbf{3 6 . 0 0}$ & $.00000^{\mathrm{a}}$ \\
\cline { 2 - 5 } & Mature & 187 & 38.00 & $.00000^{\mathrm{a}}$ \\
\hline \multirow{2}{*}{ Weight (gm) } & Immature & 13 & 3015 & 89.87 \\
\cline { 2 - 5 } & Mature & 187 & 3115 & 210.08 \\
\hline \multirow{2}{*}{ APGAR Score 1 min } & Immature & 13 & $\mathbf{5 . 3 8 5}$ & .506 \\
\cline { 2 - 5 } & Mature & 187 & 7.834 & .576 \\
\hline \multirow{2}{*}{ APGAR Score 5 min } & Immature & 13 & $\mathbf{5 . 8 4 6}$ & .801 \\
\cline { 2 - 5 } & Mature & 187 & 8.594 & .503 \\
\hline
\end{tabular}

GA: Gestational Age

Table (6) shows the mean of(GA) which was 36 week in immature group and 38 week in mature group and the mean for weight which was $3015 \mathrm{gm}$ in immature group and $3115 \mathrm{gm}$ in mature group. APGAR at 1 minute which was 5.385 in immature group and 7.834 in mature group and APGAR at 5 minutes which was 5.846 in immature group and 8.594 in mature group.

Table (7): Frequency and percent of studied groups regarding to need to NICU.

\begin{tabular}{|l|c|c|c|}
\hline \multicolumn{2}{|c|}{ Need to NICU } & Frequency & Percent \\
\hline \multirow{3}{*}{ Valid } & Yes & 13 & 6.5 \\
\cline { 2 - 4 } & No & 187 & 93.5 \\
\cline { 2 - 4 } & Total & 200 & 100.0 \\
\hline
\end{tabular}

NICU: Neonatal Intensive Care Unit

Table (7) shows frequency and percent of NICU needed by studied groups in which there was a need to NICU in 13 cases $(6.5 \%)$ and no need in 187 cases $(93.5 \%)$ from total number 200 cases $(100 \%)$. 
Table (8): Frequency and percent of studied group as regard to causes of need to NICU.

\begin{tabular}{|l|l|c|c|}
\hline \multicolumn{2}{|c|}{ Causes of NICU } & Frequency & Percent \\
\hline \multirow{4}{*}{ Valid } & TTN & 8 & 4.0 \\
\cline { 2 - 4 } & RDS & 4 & 2.0 \\
\cline { 2 - 4 } & Jaundice & 1 & 0.5 \\
\cline { 2 - 4 } & Total & 13 & 6.5 \\
\hline Missing System & 187 & 93.5 \\
\hline
\end{tabular}

NICU: Neonatal Intensive Care Unit

RDS: Respiratory Distress Syndrome

TTN: Transient Tachypnea of the Newborn

Table (8) Shows causes of need to NICU which was TTN in 8 cases $(4.0 \%)$, RDS in 4 cases $(2.0 \%)$ and Jaundice in 1 case $(0.5 \%)$ in immature group 13 cases $(6.5 \%)$ with missing system 187 cases $(93.5 \%)$ from total number 200 cases $(100 \%)$.

Figure (1): Receiver operating characteristic (ROC) curve for (EOC) of femur in differentiation between mature and immature groups.

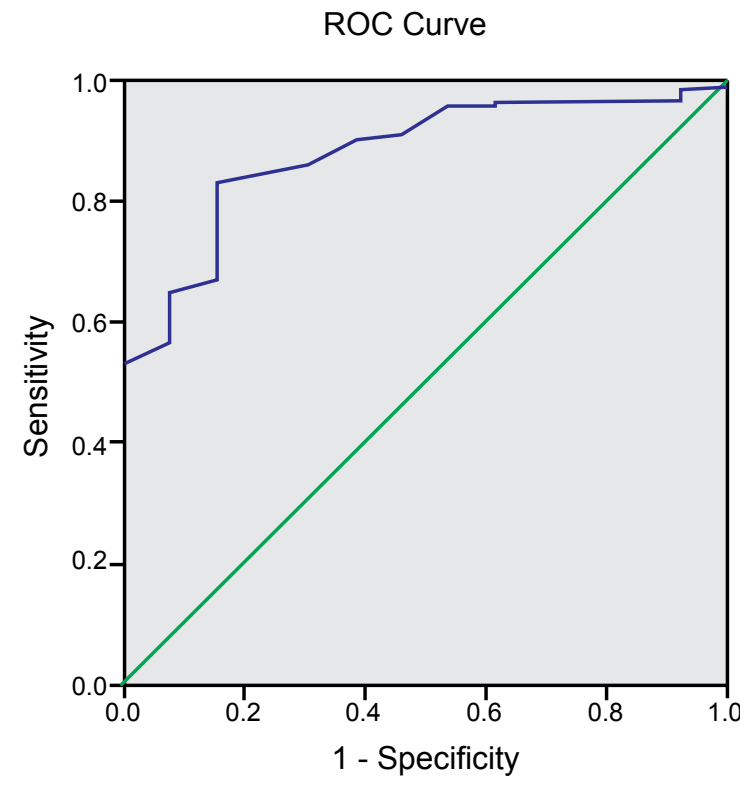

Diagonal segments are produced by ties.

\begin{tabular}{|c|c|c|c|c|c|c|c|}
\hline \multirow{2}{*}{ Cut off point } & \multirow{2}{*}{ AUC } & Sensitivity & Specificity & \multirow{2}{*}{ Std. Error } & \multirow{2}{*}{ Sig. } & \multicolumn{2}{|c|}{$\begin{array}{c}\text { Asymptotic 95\% } \\
\text { Confidence Interval }\end{array}$} \\
\cline { 5 - 8 } & & & & & $\begin{array}{c}\text { Lower } \\
\text { Bound }\end{array}$ & Upper Bound \\
\hline$<6.25$ & 0.878 & $86.1 \%$ & $70.4 \%$ & 0.039 & 0.000 & 0.802 & 0.954 \\
\hline
\end{tabular}

ROC: Receiver operating characteristic

AUC: area under the curve

Figure (1) shows that the best cut off point of size of EOC of femur at 38 weeks gestation between mature and immature group was found $<6.25 \mathrm{~mm}$ was immature and $>$ or equal to $6.25 \mathrm{~mm}$ in mature with sensitivity of $86.1 \%$ and specificity of $70.4 \%$ and area under the curve 0.878 . 
Figure (2): Receiver operating characteristic (ROC) curve for (EOC) of humerus in differentiation between mature and immature groups.

ROC Curve

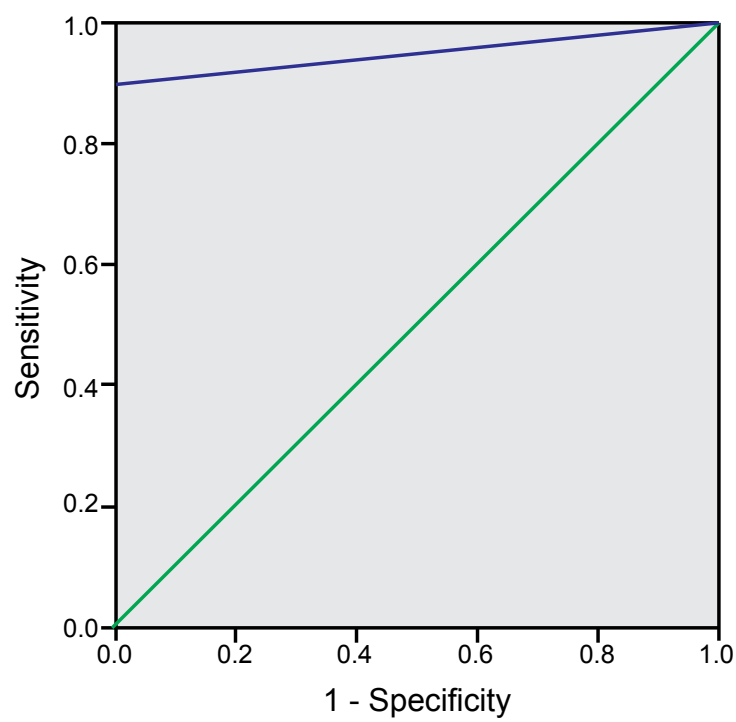

Diagonal segments are produced by ties.

\begin{tabular}{|c|c|c|c|c|c|c|c|}
\hline \multirow{2}{*}{ Cut off point } & \multirow{2}{*}{ AUC } & Sensitivity & Specificity & Std. Error $^{\mathbf{a}}$ & \multirow{2}{*}{ Sig. } & \multicolumn{2}{|c|}{$\begin{array}{c}\text { Asymptotic 95\% } \\
\text { Confidence Interval }\end{array}$} \\
\cline { 6 - 8 } & & & & & & Lower Bound & Upper Bound \\
\hline$<1.00$ & 0.949 & $90 \%$ & $100 \%$ & 0.015 & 0.000 & 0.919 & 0.980 \\
\hline
\end{tabular}

ROC: Receiver operating characteristic

AUC: area under the curve

Figure (2) shows that the best cut off point of size of EOC of humerus between mature and immature group at 38 weeks gestation was found $<1.00 \mathrm{~mm}$ in immature and $>$ or equal to $1.00 \mathrm{~mm}$ in mature with sensitivity of $90 \%$ and specificity of $100 \%$ and area under the curve of 0.949 .

Figure(3): Receiver operating characteristic (ROC) curve for (EOC) of tibia in differentiation between mature and immature groups.

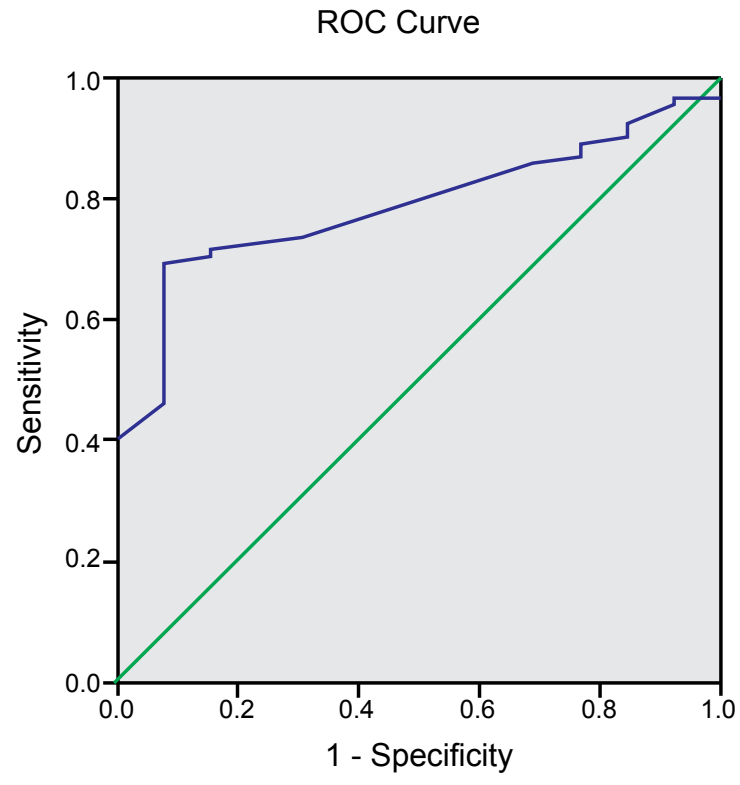

Diagonal segments are produced by ties. 


\begin{tabular}{|c|c|c|c|c|c|c|c|}
\hline \multirow{2}{*}{ Cut off point } & \multirow{2}{*}{ AUC } & \multirow{2}{*}{ Sensitivity } & \multirow{2}{*}{ Specificity } & \multirow{2}{*}{ Std. Error } & \multirow{2}{*}{ Sig. } & \multicolumn{2}{|c|}{$\begin{array}{c}\text { Asymptotic 95\% Confidence } \\
\text { Interval }\end{array}$} \\
\cline { 5 - 8 } & & & & & & Lower Bound & Upper Bound \\
\hline$<5.05$ & 0.790 & $76.5 \%$ & $61.5 \%$ & 0.034 & 0.000 & 0.705 & 0.874 \\
\hline
\end{tabular}

ROC: Receiver operating characteristic

AUC: area under the curve

Figure (3) shows that the best cut off point of size of(EOC) of tibia between mature and immature group at 38 weeks gestation was found $<5.05 \mathrm{~mm}$ in immature and $>$ or equal to $5.05 \mathrm{~mm}$ in mature with sensitivity of $76.5 \%$ and specificity of $61.5 \%$ and area under the curve of 0.790 .

Figure (4):Receiver operating characteristic (ROC) curve for total sizes of EOC of three bones in differentiation between mature and immature groups.

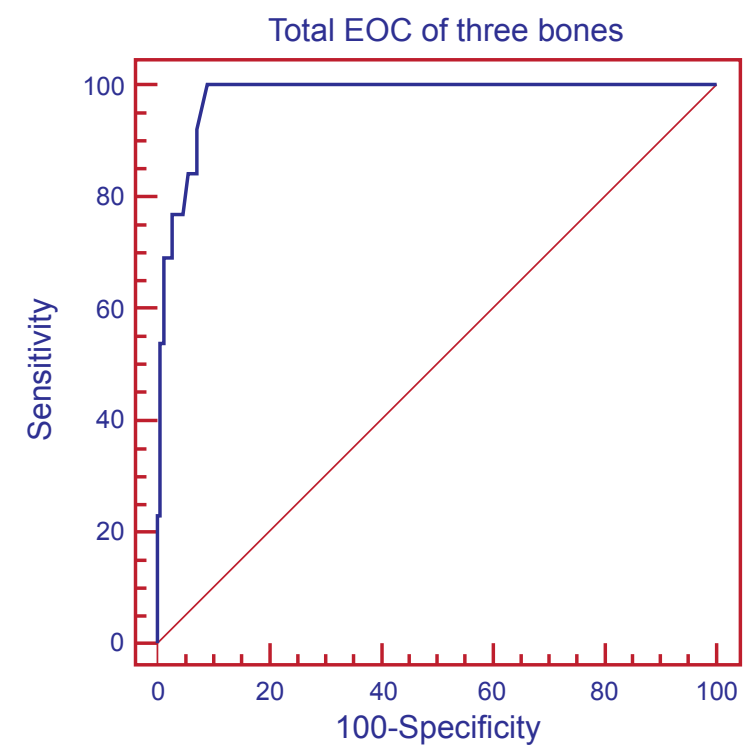

\begin{tabular}{|c|c|c|c|c|c|c|c|}
\hline \multirow{2}{*}{ Cut off point } & \multirow{2}{*}{ AUC } & \multirow{2}{*}{ Sensitivity } & \multirow{2}{*}{ Specificity } & \multirow{2}{*}{ Std. Error } & \multirow{2}{*}{ Sig. } & \multicolumn{2}{|c|}{$\begin{array}{c}\text { Asymptotic 95\% Confidence } \\
\text { Interval }\end{array}$} \\
\cline { 5 - 8 } & & & & & & Lower Bound & Upper Bound \\
\hline$<14.05$ & 0.850 & $85 \%$ & $70.2 \%$ & 0.056 & 0.000 & 0.740 & 0.960 \\
\hline
\end{tabular}

ROC: Receiver operating characteristic

AUC: area under the curve

Figure (4) shows that the best cut off point of total sizes of femur, tibia and humerus between mature and immature group at 38 weeks gestation was found $<14.05 \mathrm{~mm}$ and $>$ or equal to $14.05 \mathrm{~mm}$ in mature with sensitivity of $85 \%$ and specificity of $70.2 \%$ and area under the curve (AUC) of 0.850 .

\section{Discussion}

Fetal lung immaturity is a major problem in the management of elective birth with respect to predicting the development of infant respiratory distress syndrome (IRDS) in the neonate after birth. Although gold-standard measures of fetal lung immaturity were the chemical, biological and physical properties of amniotic fluid, the fluid was obtained by invasive technique through amniocentesis (Rasheed et al., 2012).
Further non-invasive method for evaluation of fetal lung maturity, was designed to evaluate fetal parameters by ultrasound as a marker of fetal lung maturity which is easy, safe and non-invasive (Rasheed et al., 2012).

Assessment of fetal lung maturation is one of the most important steps while deciding in birth of the fetus. The objective should be protection of the fetus from risks such as sequelae of respiratory distress syndrome ( RDS), necrotizing 
enterocolitis, intraventricular hemorrhage, patent ductus arteriozus and neonatal sepsis as much as possible. However, the main point in deciding birth is the clinical condition of the mother and the fetus (Kars et al., 2011).

Many studies of ultrasound prediction of fetal lung maturity were used to compare ultrasound parameters with tests of amniocentesis to assess that sign with lung maturity (Rasheed et al., 2012).

Saba et al., (2014) in their study concluded that ultrasound appearance and size of epiphyseal ossification centers of femur, tibia and humerus can be useful in prediction of gestational age(GA) during the third trimester of pregnancy, a period in which standard fetal biometric estimates of gestational age are least accurate. This technique appears to identify GA $<33$ wks or $>33$ wks based on the presence or absence of the distal femur epiphysis(DFE). Ultrasound visualization of proximal tibia epiphyseal (PTE) ossification is a strong indicator of GA(36)wks, where appearance of proximal humerus epiphseal (PHE) ossification virtually confirms the maturity of the fetus.

In our present study evaluate the presence and size of epiphyseal ossification centers of (femur, tibia, humerus) at 38 week of gestation and their relation to gestational age and fetal maturity. As regarding to presence of epiphyseal ossification center of femur, tibia there was no significant difference between mature and immature groups. But the size of (EOC) of femur has highly significant difference above or equal to $6.25 \mathrm{~mm}$ can be used as an ultrasonographic sign of fetal maturity. There is highly statistical significant difference found between both groups regarding presence of epiphyseal ossification center of humerus which was present in $168 / 187$ cases $(89.8 \%)$ and absent in $19 / 187(10.2 \%)$ cases of mature group versus the immature group which was absent in all cases $13 / 13(100 \%)$.

This is in agreement with Donne et al., (2005) who found that distal femoral epiphysis appeared in $17 \%$ of fetuses at 30 th week, $71 \%$ at 32 weeks' reaching to $91 \%$ at 35 weeks, and $100 \%$ at 37 weeks gestation. Proximal epiphyseal ossification center of tibia in this study appeared in $17 \%$ of fetuses at 34 weeks, $66 \%$ at 36 weeks, $80 \%$ at 37 weeks, $97 \%$ at 39 weeks, and $100 \%$ at 40 weeks' gestation. Proximal humeral epiphysis appeared in $28 \%$ at 38 weeks, $39 \%$ at 39 weeks and $55 \%$ at 40 weeks. Later appearance of (PHE) this explain why absent proximal humeral epiphysis (PHE) in 19 cases of mature group in the present study . The wide gestational range for the appearance of (DFE) unsatisfactory in assessing (GA)also explain why no significant difference between mature and immature groups as regarding to presence of epiphyseal ossification center of femur and tibia because (EOC) of tibia and femur appeared at(36) wks and( 32)wks respectively .

Saba et al., (2014) who found that the proximal humeral epiphysis (PHE) was not observed before 36 week and was observed in a small proportion of fetuses $14 \%$ at the 36th week of $\mathrm{GA}$, and this percentage increased to $25 \%$ at the 37 th, $66 \%$ at the 38 th, and $100 \%$ at the 39 th and 40th weeks, respectively. And the visualization of proximal humeral epiphysis also implies that fetus has attained maturity. Similar findings are found in Mahony BS, Callen PW et al., (2009) study which showed that all fetuses with a visible proximal humeral epiphysis (PHE) had a mature amniocentesis, a good indicator of fetal lung maturity based on L/S ratio and phosphatidyl glycerol in amniotic fluid.. Similar findings are also found in Kumari et al, (2015) who found that during ultrasonography for proximal humeral epiphysis not seen with the gestational age below 35 weeks. And also similar results are in the same line with our results in Mongolli et al, (2016) who reported confirmation of fetal maturity may also be obtained by examining the ossification centers. The distal femoral epiphysis appears at a mean age of 32-33 weeks' gestation,. Its size increases linearly with gestational age. Ultrasound detection of the proximal humeral epiphysis has been correlated with a mature amniocentesis lung profile.

According to our results we found that: the best cut off point of size of epiphyseal ossification center of femur at 38 weeks gestation between mature and immature group was found $<6.25 \mathrm{~mm}$ is immature and $>$ or equal to $6.25 \mathrm{~mm}$ is mature with sensitivity of $86.1 \%$ and specificity of $70.4 \%$. This is in agreement with Birang et al., (2013) 
who found that distal femoral epiphysis of $\geq 7$ $\mathrm{mm}$ is associated with gestational age $\geq 36$ week gestation. Suhag et al., (2016) who found that the menstrual age of a fetus whose distal femoral epiphysis measures $7 \mathrm{~mm}$ is most likely $\geq 37$ weeks. And with Mongolli et al., (2016) distal femoral epiphysis diameter greater than $7 \mathrm{~mm}$ indicates a gestational age greater than 37 weeks.

Also we found that, the best cut off point of size of epiphyseal ossification center of tibia between mature and immature group at 38 weeks gestation was $<5.05 \mathrm{~mm}$ is immature and $>$ or equal to $5.05 \mathrm{~mm}$ in mature with sensitivity of $76.5 \%$ and specificity of $61.5 \%$. This is in agreement with Tabsh., (1984) demonstrated a mature L/S ratio in $100 \%$ of cases in which the proximal tibial epiphysis was $\geq 5 \mathrm{~mm}$ in diameter in $95 \%$ of cases. In the current study we found that the best cut off point of size of epiphyseal ossification center of humerus between mature and immature group at 38 weeks gestation was found $<1.00 \mathrm{~mm}$ is immature and $>$ or equal to $1.00 \mathrm{~mm}$ in mature with sensitivity of $90 \%$ and specificity of $100 \%$.

In the present study we found that the best cut off point of total sizes of femur, tibia and humerus between mature and immature group at 38 weeks gestation was found $<14.05 \mathrm{~mm}$ in immature and $>$ or equal to $14.05 \mathrm{~mm}$ in mature with sensitivity of $85 \%$ and specificity of $70.2 \%$. This is in disagreement with Saba et al., (2014) who found that the sum of the three epiphyseal ossification centers (distal femoral, proximal tibial and proximal humeral epiphyseal ossification centers) can also be useful in prediction of GA particularly the all-important GA of 37 weeks of fetal maturity. The mean sum of epiphyseal ossification centers (distal femoral, proximal tibial and humeral epiphyseal ossification centers) for GA of 37-38 weeks was $34 \mathrm{~mm}$. And also not in the same line with Kumari et al., (2015) had found the gestational age correlated well with the sum of the diameters of the three ossification centers (distal femoral, proximal tibial and proximal humeral epiphyseal ossification centers). Positive predictive values of the fetus having gestational age of at least 37 weeks when the sum of the three centers was 7,11 , and $13 \mathrm{~mm}$ were $82 \%, 94 \%$, and $100 \%$, respectively.
There was highly statistically significant found between the mature and the immature group as regard to epiphyseal ossification centers( EOC) size of femur, tibia, humerus and total sizes of three bones which was significantly decreased in immature than mature group. This is agreement with Goldstein et al., (2009) in their study concluded that EOC increase in size and are more echo-dense in appearance with progressive gestational age. Mongolli et al. (2016) who found that distal femoral epiphysis size increases linearly with gestational age.

\section{Conclusion}

Confirmation of fetal maturity obtained by fetal biometry and ultrasound visualization and measurement of size of the epiphyseal ossification centers of long bones (femur-tibia-humerus) can be used as a tool for estimation of fetal maturity at 38 wks before elective cesarean section.

\section{$\underline{\text { References }}$}

1. Birang S, Ali AA and Nazmi Z (2013):Distal femoral epiphyses ossification center diameter and third trimester gestational age in Iranian population. Gineekologia Polska 84, 10251029.

2. Donne HD, Faundes A, Tristao EG, de Sousa MH and Urbanetz AA (2005): Sonographic identification and measurement of the epiphyseal ossification centers as markers of fetal gestational age. J Clin Ultrasound. 33(8):394400.

3. Fariba K, Fateme A, Shamsi A, Zahra F, Shamsi G and Parvin S (2016): Predicting Fetal Lung Maturity Using The Fetal Main Pulmonary Artery Doppler Indices. Acta Medica Mediterranea; 32: 921.

4. Gillen-Goldstein J, MacKenzie AP, Funai EF (2016):Assessment of fetal lung maturity. Topic 405 Version 17.

5. Goldstein I, Lockwood C, Belanger $\mathbf{K}$, Hobbins J (2009): Ultrasonographic assessment of gestational age with the distal femoral and proximal tibial ossification centers in the third trimester. Am J Obstet Gynecol 1988, 158(1):127-30electronic( cited on2009 jul 06). 
Available from URL:http//www.pubmed.com. htm .

6. Kars B, Yasemin A, Karsidag K, Buyukbayrak EE, Telatar $B$ and Turan $C$ (2011): Evaluation of Fetal Lung Maturity By Turbidity Testing And Tap Test Journal of Turkish Society of Obstetrics and Gynecology, (J Turk Soc Obstet Gynecol); 8(1): 25- 31.

7. Kumari R, Yadav AK, Bhandari K, Kumari HN and Rajni (2015): Ossification Centers of Distal Femur, Proximal Tibia And Proximal Humerus As A Tool For Estimating Gestational Age Of Fetuses In Third Trimester Of Pregnancy in West Indian population. International Journal of Basic and Applied Medical Sciences ISSN: 2277-2103(online) An Open Access ,Online Intrernational Journal Available at htt// www.cibteck.org/jms.htm 5(2),p 316-321.

8. Mahony BS, Bowie JD, Killam AP and Kay HH.,(2009): Epiphyseal ossification center in the assessment of fetal maturity,sonographic correlation with amniocentesis lung profile. Radiol (serial online) 1986 May (cited 2009 Jul 5); 159(2):521-4. available from: URL:http// www.radiology .com.htm.
9. Mahony BS, Callen PW and Filly RA (2009): The distal femoral epiphyseal ossification center in the assessment of third-trimester menstrual age: sonographic identification and measurement. Radiol (serial online) 1985 Apr (cited 2009 Jul5); 155(1): 201-4 available from: URL:http//www.radiology .com.htm.

10. Mongolli M, MBBS DM (2016): Evaluation of Gestation. Clinical Methods of Estimating Gestational Age. Medescape.

11. Rasheed FA, Zahraa'M AS and Hussain SA (2012): "Evaluation of thalamus echogenicity by ultrasound as a marker of fetal lung maturity." Open Journal of Obstetrics and Gynecology; 2: no. 03: 270.

12.Saba S, Muhammad IC, Abdul HS, Abdul RL and Ahmed HS (2014): Ultrasonographic Appearance and Measurement of Epiphyseal Ossification Centres of Fetal Peripheral Long Bones for Assessment of gestational age.http:/ www. Medical forum Monthly. A jornal For All Specialists,P 1-10.

13.Suhag AH, Channar MI and Lakho AR (2016): Fetal biometry in the third trimester. www.meforum.pk/index.database9-articles/ 79.

14. Tabsh KMA (1984):Correlation of ultrasonic epiphyseal centers and lecithin/sphingomeylin ratio. Obstet Gynecol; 64: 92. 